\title{
Intelligent Positioning Fuzzy Servomechanism Under PWM Nonlinear Loads
}

\author{
D.Rangel $^{1,2}$, A. L. Rivera ${ }^{2}$, P.D. Alaníz ${ }^{1}$, R. Castañeda $^{1}$, V.M. Castaño* ${ }^{2}$ \\ ${ }^{1}$ DEPFI, Facultad de Ingeniería, Universidad Autónoma de Querétaro, Cerro de las Campanas S/N, Ciudad Universitaria, \\ Querétaro, Qro., CP 76010, México. \\ ${ }^{2}$ Centro de Física Aplicada y Tecnología Avanzada, Universidad Nacional Autónoma de México, \\ Apartado Postal 1-1010, Querétaro, Qro., CP 76000, México. \\ *meneses@servidor.unam.mx
}

\begin{abstract}
An experimental intelligent angular positioning fuzzy servomechanism excited by a nonlinear load based on a mechanical transient Pulse Width Modulation (PWM) is developed. This fuzzy positioning system is capable of reaching the angular position with high precision even when the response is affected by the application of different PWM nonlinear loads.
\end{abstract}

Keywords: Fuzzy servomechanism, nonlinear load, fuzzy rotating control.

\section{RESUMEN}

Se desarrolla un servomecanismo difuso de posicionamiento angular inteligente experimental perturbado por cargas no-lineales basadas en transitorios mecánicos generados mediante la modulación de ancho de pulso (PWM). El sistema de posicionamiento difuso desarrollado es capaz de alcanzar la posición angular con gran precisión aún cuando la respuesta es afectada por la aplicación de distintas cargas PWM no lineales.

\section{Introduction}

Angular positioning mechatronic systems, formed by an actuator device, a transmission system and a mechanical load, are one of the most common parts in robotized manufacturing, materials processing and servo-controlled fluid supplying systems. These systems require coupling of the strong variable loads in order to obtain high order dynamic positioning mechanisms. This is commonly achieved by Proportional-IntegralDerivative (PID) strategy control [1], but its functionality is restricted when it is implemented for controlling nonlinear plants because its dynamic range is reduced. To describe such a system, fourth-order models [2], complex dynamic servo-valve torque motor modeling [3], adaptative intelligent control using self-calibration [4], speed feedback [5], and fuzzy servomechanisms [6, 7] are used. Fuzzy control [8] ensures precise tracking of the prescribed motion while preserving the dynamic balance [9] and it can handle precise position control even in the presence of stick-slip and friction.

Industrial applications usually need mechanisms for covering multiples aspects of simple implementation [10], especially for precision positioning. Conventional step motors are widely used in precision positioning applications, but they are vulnerable to input random signals in open loop control [11]. To overcome this problem, a PID closed loop control system is utilized to reduce the white noise. Although the PID controller is a robust control scheme, it cannot overcome the error introduced by implementing white noise on the phase currents of the stepper motor, thus complex control algorithms have been developed for pneumatic servo-positioning [12]. These trials are unable to handle the nonlinearities of the systems, such as the friction force, which restricts position accuracy. Another assessment is a nonlinear control technique using backstepping design under non strict-feedback form, which was synthesized 
and implemented for controlling the tracking position of an electropneumatic system [13]. Other proposals include a modular high-precision control system with an integrated motor [14] and the use of an intelligent control $[15,16]$. Nevertheless, currently the most promising control systems for strong nonlinear loads of dynamic positioning systems have used fuzzy logic [8]. However, fuzzy logic has not been implemented for precise angular positioning.

This paper describes an experimental intelligent robust fuzzy rotating servomechanism for precise angular positioning, coupled to a novel mechanical transient Pulse Width Modulation (PWM) nonlinear load, which is generated digitally. This precise intelligent angular positioning system can be used in high order dynamic rotating mechatronic systems and automotive servomechanisms with a nonlinear mechanical load. To verify the accuracy of the proposed system, it is compared with traditional PID positioning for $90^{\circ}$ considering the servomechanism working without load and under nonlinear load type exponential or logarithmic.

\section{Theory}

Fuzzy Logic is a methodology that enables users to describe a desired system's behavior by means of variables which can take any real value in the interval $[0,1]$. This is in contrast with the usual binary logic in which the variables may have a membership value of 0 or 1 [17]. Fuzzy Logic Control (FLC) consists of three basic components [8]:

- the fuzzification that transforms the analog input signal into a linguistic fuzzy variable between 0 and 1 , the so-called membership function $(\mu)$,

- the fuzzy engine which handles the fuzzy sets and inference with if-then rules, and
- the defuzzification which transforms the fuzzy control actions to a crisp signal that can be applied as feedback to the system.

Here a fuzzy logic control of the Mamdani type is used [18], which consists of a set of linguistic statements composed of two inputs, the position error $(e)$, and the rate of the position error value $(\Delta e)$, in order to carry out control actions by using if-then rules. The inputs in the approach are e and $\Delta e$ at a sampling time $(t)$, while the output is the control signal $(u)$. At the sampling point $k$,

$e(k)=\theta_{d}(k)-\theta_{c}(k)$

$\Delta e(k)=e(k)-e(k-1)$

where $\theta_{\mathrm{d}}(k)$ is the desired angular position, $\theta_{\mathrm{c}}(k)$ is the current angular position, $\mathrm{e}(\mathrm{k})$ is the current error and $e(k-1)$ is the error in the previous sampling time. To describe the loads and responses of the positioning mechanism standard signal analysis techniques were used.

\section{Experimental setup}

The robust servomechanism for precision angular positioning, shown in Figure 1, is composed of a 2pole $12 \mathrm{~V}$ - $2800 \mathrm{rpm}$ DC permanent magnet gear head torque motor with a $0.845 \mathrm{rev} / \mathrm{s}$ reduction coupled to the nonlinear PWM mechanical load through a 24 turn stainless steel torsion spring. The load motor is a 4-Pole, $24 \mathrm{~V}-1800 \mathrm{rpm}$ DC permanent magnet, which has two different digital signals as inputs specially generated on a single low cost stand-alone microcontroller. A PC-based fuzzy control is used to reach the precise positioning within a closed loop. The angular position is counted by an incremental quadrature encoder hollow-shaft Dynapar HS-35 installed on the drive shaft. Since the positioning resolution is 1024 pulses per revolution, a 6221 NI-USB DI/O is used for encoding the actual position. The PWM 


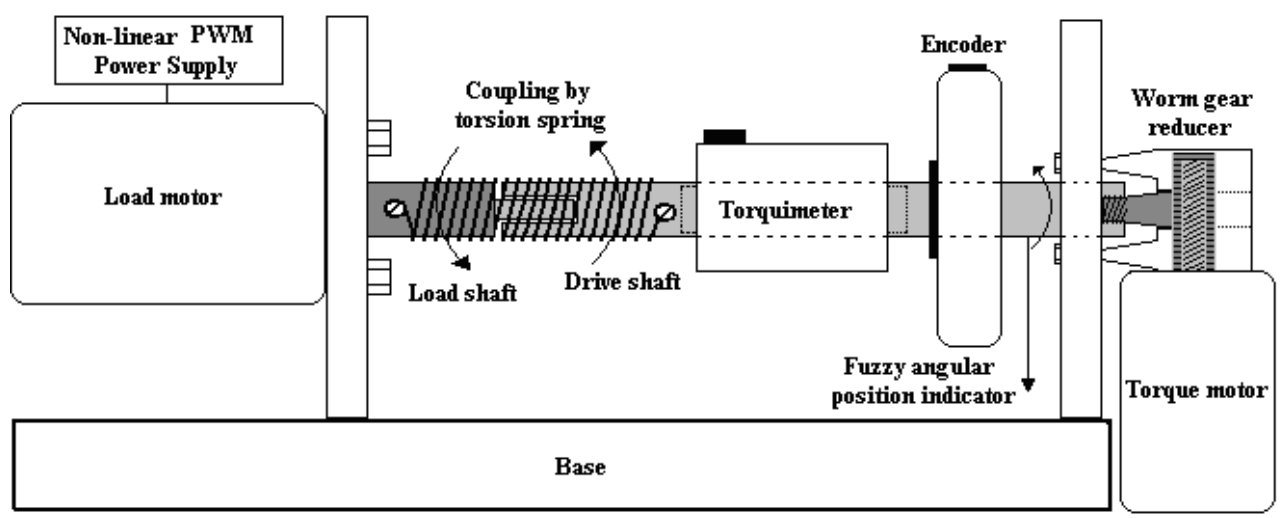

Figure 1. Fuzzy positioning system (lateral view).

control voltage of the torque motor at $15 \mathrm{KHz}$ is calculated using a Lab View fuzzy logic control software based on the fuzzy inference and the weight rule, depending on how many torque conditions are required due to the action of the nonlinear PWM load during the trajectory reaching. The angular trajectory ranges from 0 up to 1 revolution. Position parameters such as the current of the torque motor, the dynamic torque and the reached position are PC-monitored at 1 ms sampling time measured by means of the torque sensor with a socket wrench Lebow 1254305 placed between the torque motor and the nonlinear PWM mechanical load.

In order to define the fuzzification, i.e. the input membership functions for the position error and the rate position error to the fuzzy controller, the positioning universe was divided into seven domains which are negative big (NB), negative medium (NM), negative small (NS), zero (Z), positive small (PS), positive medium (PM), and positive big (PB). For the angular velocity, the universe was divided into three domains which are negative $(\mathrm{N})$, zero $(\mathrm{Z})$, and positive $(\mathrm{P})$ as is shown in Figure 2. To simplify the computation of the fuzzy algorithm, triangular membership functions were employed which are processed by means of the Fuzzy Toolkit using the Lab View software.
The membership function processed by the fuzzy logic algorithm produces the PWM Singletons taken as output assignments for the control voltage at $0 \%, 20 \%, 50 \%$, and $99 \%$ PWM. The peaks of the triangular membership functions were placed according to the dynamic response to intelligently increase the delivered energy to the torque motor. The fuzzy associated matrix was built into several nonlinear load conditions by using linguistic information derived from a human operator. In this paper only 21 fuzzy rules were employed to manipulate the servomechanism by changing nonlinearly the duty cycle percent. These fuzzy rules are summarized in Table 1 . On each nonlinear load condition, both inputs, in rules form, are evaluated by the control software and the information, in linguistic form, is converted to a membership function ranging from 0 to 1 , according to the weight of each rule in the output system. The algorithm used for inference is the MAX-MIN method that interprets these rules and assigns a singleton PWM percent as the control voltage. As the control output is in singleton mode an explicit defuzzification method is not necessary. Both the fuzzification and inference stages were tuned on experimentally. Counterclockwise and clockwise rotations are defined as positive and negative, respectively. 


\section{Intelligent Positioning Fuzzy Servomechanism Under PWM Nonlinear Loads, D.Rangel et al., 87-100}
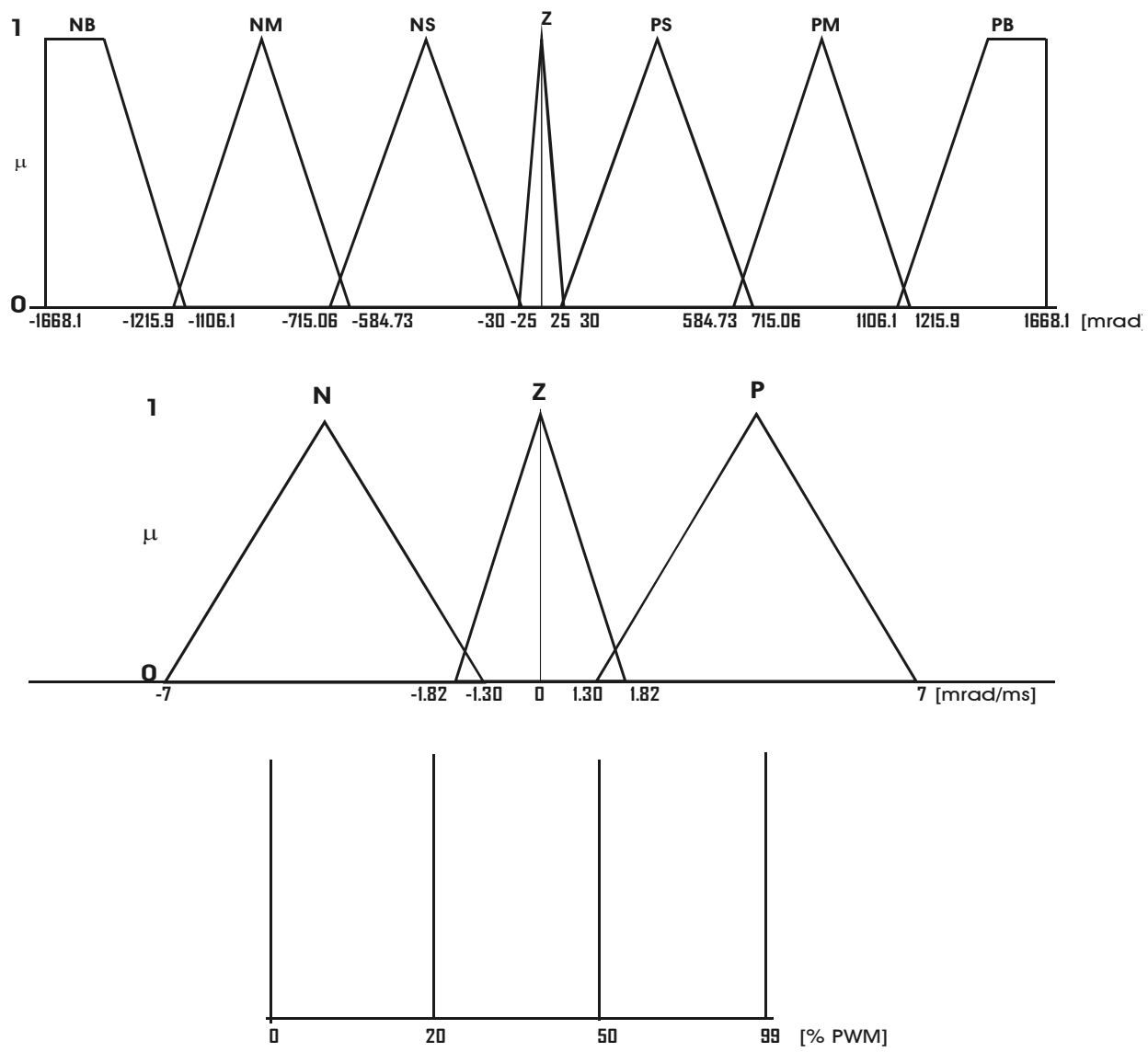

Figure 2. Fuzzy inputs and outputs variables membership functions.

\begin{tabular}{|c|c|c|c|}
\hline$e \frac{\Delta e}{\Delta t}$ & $\mathrm{P}$ & $\mathrm{Z}$ & $\mathrm{N}$ \\
\hline $\mathrm{NB}$ & 0.99 & 0.99 & 0.99 \\
\hline NM & 0.50 & 0.50 & 0.50 \\
\hline NS & 0.50 & 0.20 & 0.20 \\
\hline $\mathrm{Z}$ & -0.20 & 0 & 0.20 \\
\hline PS & -0.20 & -0.20 & -0.20 \\
\hline PM & -0.50 & -0.50 & -0.50 \\
\hline PB & -0.99 & -0.99 & -0.99 \\
\hline
\end{tabular}

Table 1. Fuzzy associated matrix for $90^{\circ}$ angular positioning with duty cycle values. 
A strong nonlinear mechanical load is generated by modifying the conventional PWM waveform. The PWM technique is widely used as the control voltage signal in DC motors and servomotors due to the excellent linearity of its mean value against the duty cycle [1]. Here, the nonlinear increment of the PWM duty cycle is modified using exponential and logarithmic functions discretely generated and modified on a single chip of the PWM microcontroller module (see Figure 3). The total time interval in which the PWM duty cycle goes from 0 to $100 \%$ was calculated at $765 \mathrm{~ms}$ to induce a nonlinear transient effect on the load motor. The frequency of the PWM load signal at 60 $\mathrm{Hz}$ is applied to the DC Load Motor using a power driver circuit. While the PWM excitation signal is applied to the load motor, it opposes to the angular positioning of the torque motor as a perturbation in the transient response stage of the position servomechanism.
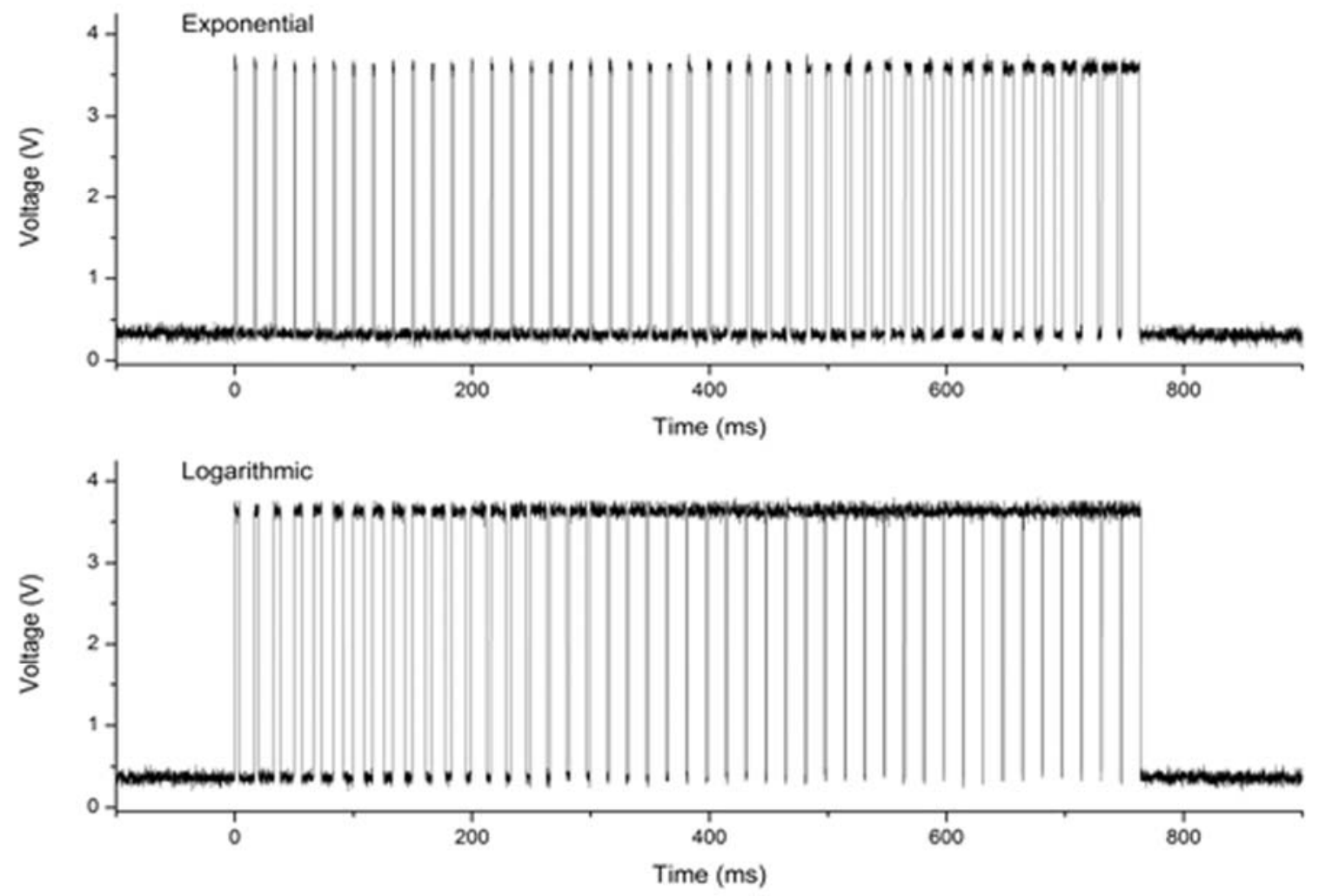

Figure 3. Exponential and logarithmic PWM excitation signals applied to the load motor. 


\section{Intelligent Positioning Fuzzy Servomechanism Under PWM Nonlinear Loads, D.Rangel et al., 87-100}

\section{Results and discussion}

To verify the performance of the proposed fuzzy angular positioning servomechanism without load, it is managed to reach $90^{\circ}$ comparing its behavior with the standard technique of ProportionalIntegral-Derivative (PID) strategy control. 30 repetitions of each test were made to obtain the characteristic parameters of the system (overshoot, settling time and steady state position). This assures, in accordance to the large numbers theorem of statistics [19], that the parameters correctly describe the behavior of the system.

Because the performance of the angular positioning servomechanism is significantly affected by the transient PWM mechanical load, two different types of loads, exponential and logarithmic, were applied as perturbations during the positioning at an angular position of $90^{\circ}$. For each test, the fuzzy rule-based algorithm was optimized to achieve acceptable performance and repeatability. The control software uses Lab View v. 8.2, and the fuzzy toolkit window is employed to construct the fuzzification, the inference and the defuzzification. The transient response speed, the overshoot value and the steady angular position error are selected as the performance indices of this controller with a sampling frequency of $1 \mathrm{kHz}$. Statistical analysis is performed using Excel 2007 and Origin Pro v. 8. Each test is repeated 30 times to obtain characteristic parameters and is compared with PID control experiments under the same loads.
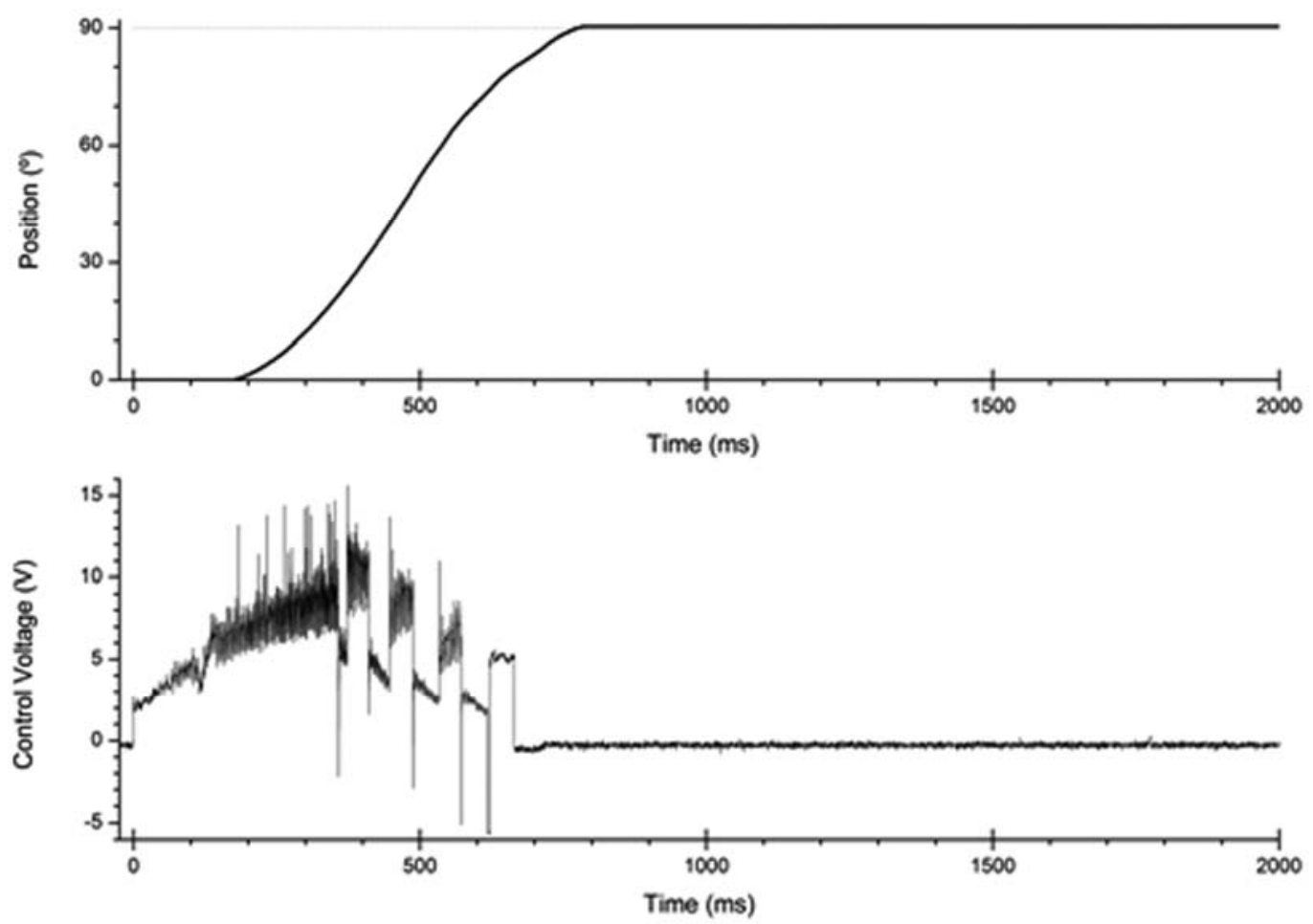

Figure 4. Typical $90^{\circ}$ fuzzy positioning responses without load, position $\left({ }^{\circ}\right)$ and PWM control voltage (V) as function of time (ms). 
Figure 4 shows the response of the fuzzy system without load for angular positioning at $90^{\circ}$. In this figure, the position response shows a dead-zone at an early stage, suggesting an inertial behavior according to the gear transmission reduction rate. The PWM control voltage that is in singleton mode is calculated by means of the fuzzy control algorithm considering the weight rule, inference and specified fuzzification method. Without load, the PWM control voltage is also shown in Figure 4. The control law history, as the control voltage, observed in Figure 4, shows the transient effect with the maximum PWM at early stages. To see the positioning angular error in the fuzzy system without load, 30 repetitions of the test were evaluated . In Figure 5, it is presented a zoom of the behavior around the steady state value of the mean of the entire tests with error bars evaluated as the standard deviation of the data. From the figure, it is clear that the desired position $\left(90^{\circ}\right)$ is achieved with high stability and low error (of $\left.0.45^{\circ}\right)$.

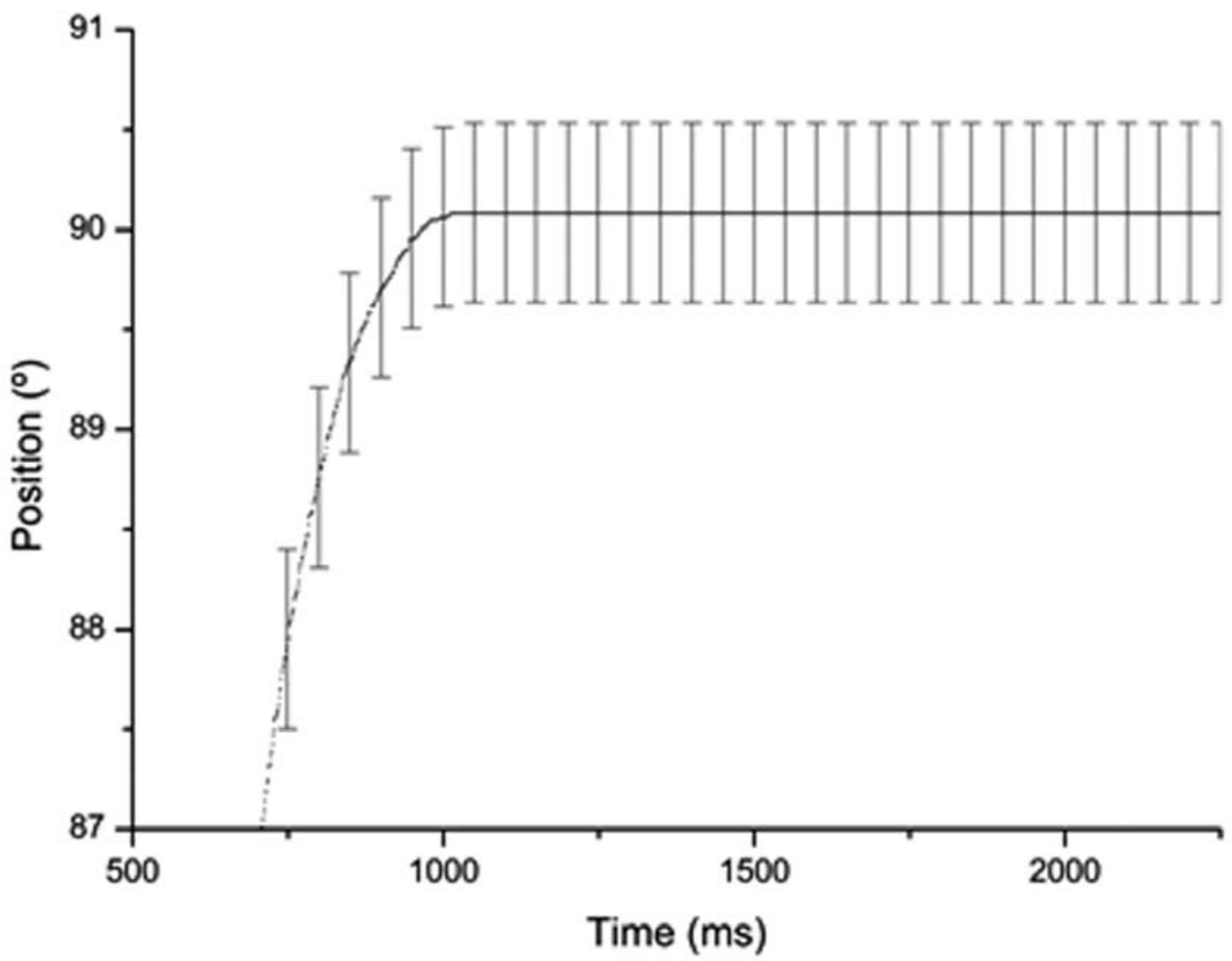

Figure 5. Typical fuzzy angular position with its associated error as function of time for a system without load. 


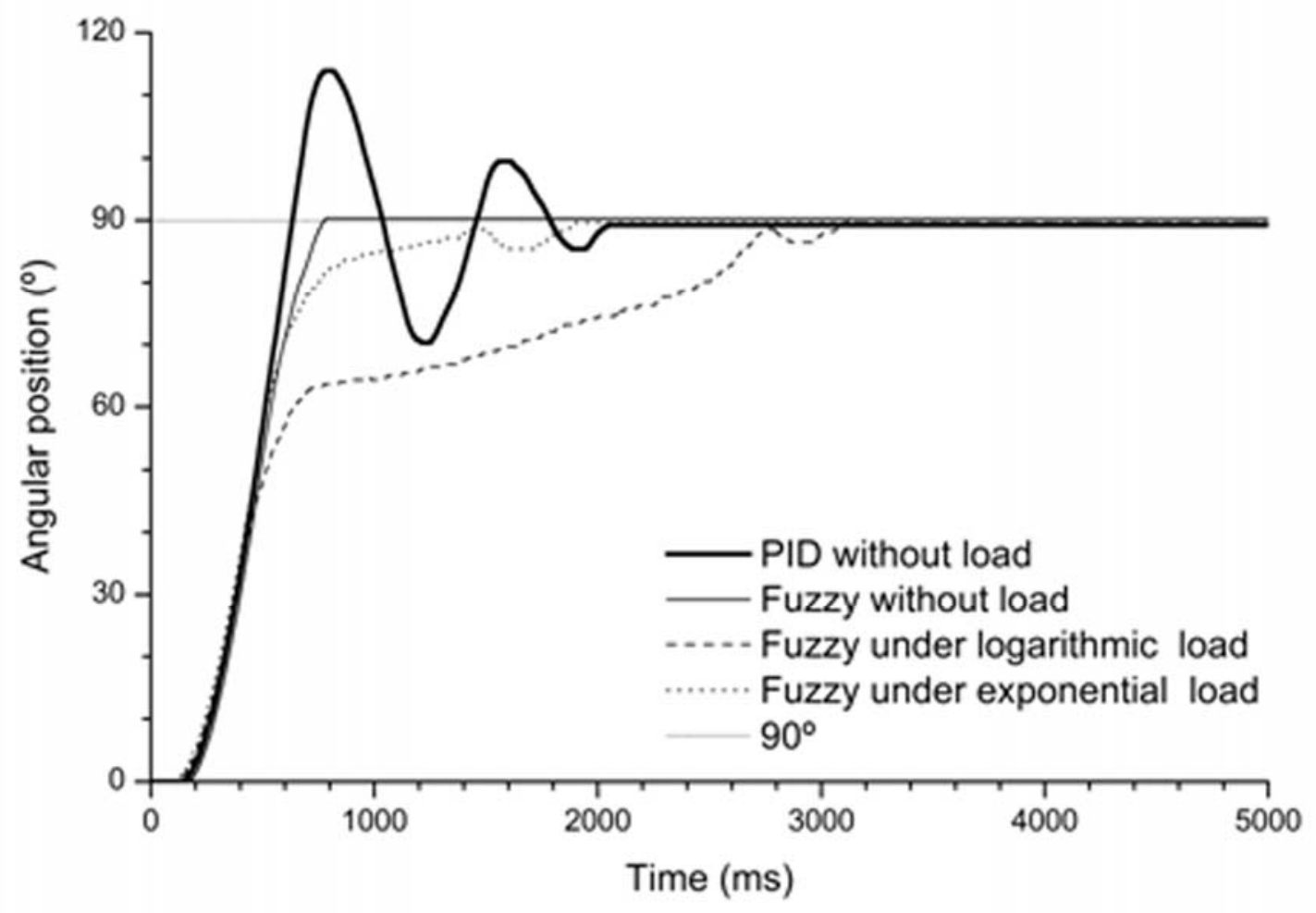

Figure 6. Typical $90^{\circ}$ angular positioning responses for PID control without load, fuzzy servomechanism without load, under exponential and logarithmic loads.

The position angular responses of the experimental servomechanism for $90^{\circ}$ positioning with PID and the fuzzy control without load, fuzzy with a mechanical exponential and logarithmic loads applied after $500 \mathrm{~ms}$, at the rising time stage, are shown in Figure 6.

For a system without load, the fuzzy control shows a better behavior than PID because it does not have overshoot, it does not oscillate to reach the final position, and it is closer to the desired angular position. Regardless the type of load, the system under fuzzy control reaches the desired angle with acceptable precision and with a relative position steady state error of less than $1 \%$. It is observed that the exponential load practically does not affect the angular positioning because only a little disturbance appears, while the logarithmic load is the most important transient effect on the fuzzy servomechanism.

The control voltage that is provided in singleton mode under exponential and logarithmic loads is shown in Figure 7. Here, it is also confirmed that the stronger perturbation is due to logarithmic load. The area under the PWM control voltage curve in this case indicates that the logarithmic load needs more power than the exponential load to achieve the final position. 

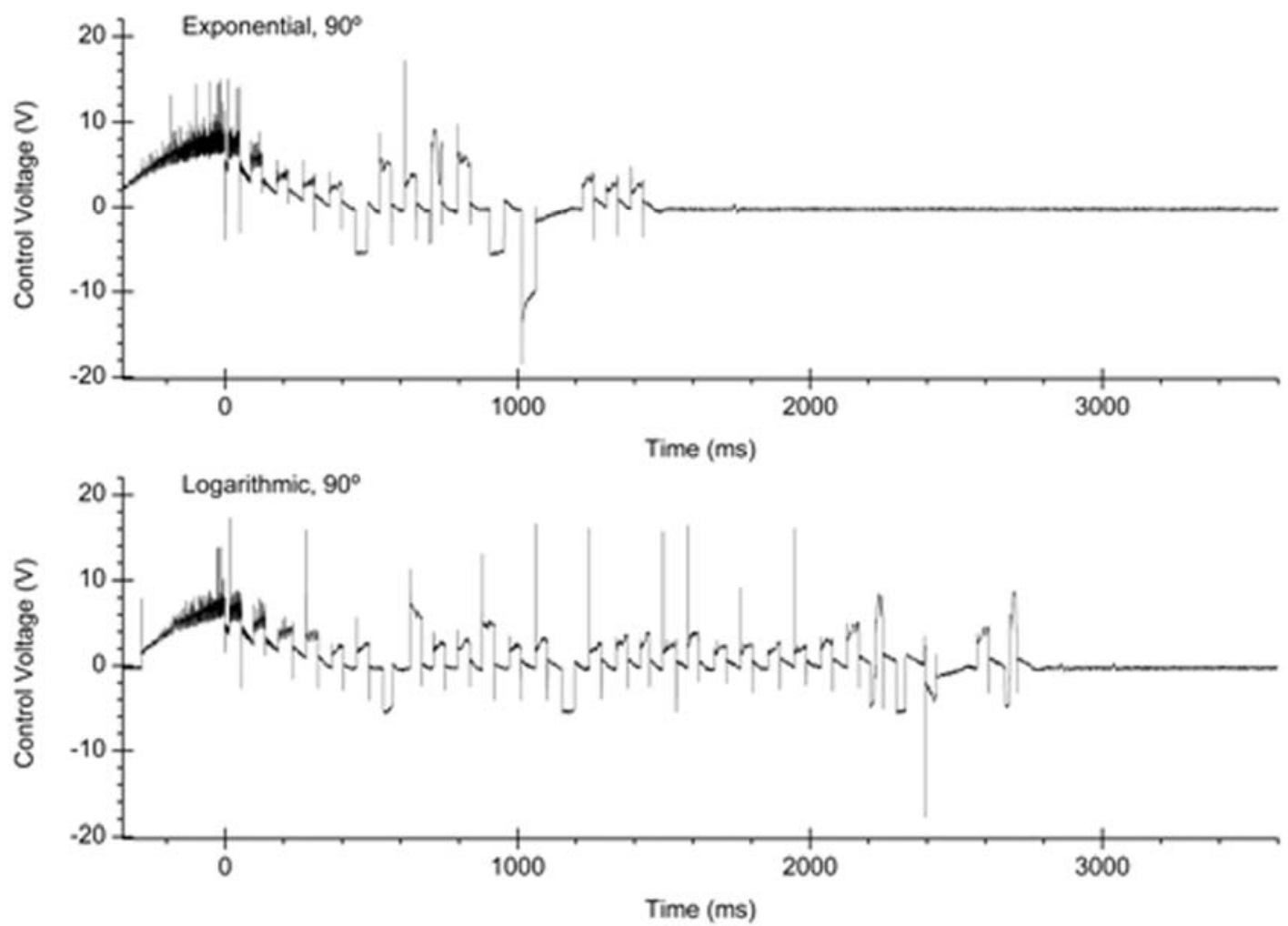

Figure 7. PWM control voltage under exponential and logarithmic loads at $90^{\circ}$.

\begin{tabular}{|l|l|c|c|c|c|}
\hline $\begin{array}{c}\text { CONTROL } \\
\text { SCHEME }\end{array}$ & LOAD TYPE & OVERSHOOT & $\begin{array}{c}\text { STEADY STATE } \\
\text { POSITION }\end{array}$ & $\begin{array}{c}\text { STEADY } \\
\text { STATE } \\
\text { ERROR }\end{array}$ & $\begin{array}{c}\text { SETTLING } \\
\text { TIME }\end{array}$ \\
\hline \multirow{4}{*}{ FUZZY } & Without & $0.1^{\circ} \pm 0.21^{\circ}$ & $90.1^{\circ} \pm 0.45^{\circ}$ & $0.1^{\circ} \pm 0.5^{\circ}$ & $780 \mathrm{~ms}$ \\
\cline { 2 - 6 } & Exponential & $0.3^{\circ} \pm 0.59^{\circ}$ & $90^{\circ} \pm 1.3^{\circ}$ & $0^{\circ} \pm 1^{\circ}$ & $2050 \mathrm{~ms}$ \\
\cline { 2 - 6 } & Logarithmic & $1.2^{\circ} \pm 0.53^{\circ}$ & $92^{\circ} \pm 2.3$ & $2^{\circ} \pm 2^{\circ}$ & $2920 \mathrm{~ms}$ \\
\hline \multirow{3}{*}{ PID } & Without & $10^{\circ} \pm 10^{\circ}$ & $91^{\circ} \pm 2.0^{\circ}$ & $4^{\circ} \pm 11^{\circ}$ & $1100 \mathrm{~ms}$ \\
\cline { 2 - 6 } & Exponential & $9^{\circ} \pm 6.1^{\circ}$ & $89^{\circ} \pm 2.8^{\circ}$ & $1^{\circ} \pm 3^{\circ}$ & $1560 \mathrm{~ms}$ \\
\cline { 2 - 6 } & Logarithmic & $1.7^{\circ} \pm 1.3^{\circ}$ & $89^{\circ} \pm 3.0 \circ$ & $2^{\circ} \pm 3^{\circ}$ & $1720 \mathrm{~ms}$ \\
\hline
\end{tabular}

Table 2. Performance parameters of the angular positioning servomechanism at $90^{\circ}$. 
The control parameters (overshoot, steady state position, steady state error and settling time) of the responses without load and under logarithmic and exponential loads for $90^{\circ}$ angular positioning managed by fuzzy and PID controls are presented in Table 2. As expected, the load changes affect the behavior of the parameters. The strongest changes in the performance are produced by the logarithmic load. In all the cases, the fuzzy control has better performance than PID because it is more stable, has lower overshoot and minor angular positioning error.

For all loads under fuzzy control, the overshoot is almost zero, while the PID control has a higher overload and presents oscillations due to the lack of optimum tuning of the proportional constant, the integral time and the derivative time. Overshoot is an important parameter that has to be minimized in all control algorithms because it increases the production costs in the industry. For example, in the case of a dosage servo-valve, overshoot of the position implies more volume supply. In this case, the proposed fuzzy system can be implemented for a correct fluid dosage or an automated component mixture.

For all loads, the fuzzy control has a better positioning performance than PID because the relative position steady state error is less than $2 \%$ for the fuzzy system. In automated manufacturing systems, it is important to obtain stable angular positioning under the presence of nonlinear transients like the viscous friction produced by the change of temperature of the friction elements in the bearings or shafts of the servo-motors. In this sense, it is more reliable to implement the fuzzy control than PID.

\section{Conclusions}

A fuzzy servomechanism for angular positioning was designed to achieve high precision, in spite of the presence of any strong nonlinear perturbations such as logarithm and exponential PWM mechanical loads, soft coupling and dynamic friction. The whole model of the fuzzy servomechanism allows the control of difficult nonlinear loads which are almost impossible to handle by a conventional scheme as PID.

In order to evaluate the robustness of the fuzzy servomechanism for angular positioning, exponential and logarithmic loads were applied on the worst torque condition, at the beginning, to reach $90^{\circ}$, and its performance was compared with the traditional PID control. Many practical nonlinear loads act within the two extreme situations which were analyzed here (exponential and logarithmic) permitting the employment of this methodology in a wide variety of applications.

The fuzzy algorithm worked with an angular positioning error of less than $2 \%$ when the rule based fuzzy control is optimized for interacting with a human operator in a real time response. The PID's angular positioning error was worst in all the cases. Moreover, the fuzzy system has higher repeatability than PID as shown by the smaller standard deviation of the 30 tests to reach $90^{\circ}$.

Another advantage of the fuzzy system is that practically almost zero overshoot is observed in the positioning changes, while PID has significant overshoots.

Logarithmic loads have greater influence for achieving the positions. All loads delay the angular position time of the fuzzy servomechanism. The logarithmic load is the most important transient effect on the fuzzy servomechanism. 
The settling time without load is less for the fuzzy control; however, PID has smaller settling times under exponential and logarithmic loads. Nevertheless, the priority in this work is to control the precision positioning and not the speed of positioning and, in this sense, the fuzzy control is better than PID.

Then, the fuzzy servomechanism for angular positioning proposed here has high precision, good repeatability, and almost zero overshoot without loads or under strong nonlinear perturbations such as logarithm and exponential PWM mechanical loads.

\section{References}

[1] Johnson, D.E., Johnson, J.R., Hilburn, J.L., Scott, P.D., Electric Circuit Analysis, 3d Ed, John Wiley \& Sons, New York, USA, 1999, pp. 848.

[2] Job, V.A., Mechatronic design, Mechatronics, Vol. 13, No. 10, December, 2003, pp. 1045-1066.

[3] Li, S., Song, Y., Dynamic response of a hydraulic servo-valve torque motor with magnetic fluids, Mechatronics, Vol. 17, No. 8, October, 2007, pp. 442447.

[4] Cecco, M., Debei, S., Zaccariotto, M., Adaptiverandomized self-calibration of electromechanical shutters for space imaging, Mechanical Systems and Signal Processing, Vol. 20, November, 2006, pp. 23052320.

[5] Stosky, A., Solyom, S., Kolmanovsky, I., Engine control using speed feedback, International Journal of Automotive Technology, Vol. 8, No. 4, 2007, pp. 477481.

[6] Huang, S.J., Wang, S.S., Mechatronics and control of a long-range nanometer positioning servomechanism, Mechatronics, Vol. 19, No. 1, February, 2009, pp. 14-28.
[7] Zhao, Y.S., Chen, L.P., Zhang, Y.Q., Yang, J., Enhanced fuzzy sliding mode controller for launch control of AMT vehicle using a brushless DC motor drive, International Journal of Automotive Technology, Vol. 8, No. 3, 2007, pp. 383-394.

[8] Tanaka, K., Wang, H.O., Fuzzy control systems design and analysis: a linear matrix inequality approach, Wiley Inter-Science, New York, 2001, pp. 305.

[9] Dusko, M.K., Aleksandar, D.R., Miomir, K.V., Hybrid dynamic control algorithm for humanoid robots based on reinforcement learning, Journal of Intelligent and Robotic Systems, Vol. 51, No. 1, January, 2008, pp. 3-30.

[10] González, G., Canales, A., León, A, Morales, J. R., Design of a torque generating system, Journal of Applied Research and Technology, Vol. 5, No. 2, August, 2007, pp. 65-73.

[11] Ali, S.G., Mehdi, B., Investigation of the micro-step control positioning system performance affected by random input signals, Mechatronics, Vol. 15, No. 10, 2005, pp. 1175-1189.

[12] Chiang, M.H., Chen, C.C., Tsou, T.N., Large stroke and high precision pneumatic-piezoelectric hybrid positioning control using adaptive discrete variable structure control, Mechatronics, Vol. 15, No. 5, 2005, pp. 523-545.

[13] Smaoui, M., Brun, X., Thomasset, D., A study of tracking position of an electropneumatic system using backstepping design, Control Engineering Practice, Vol. 14, No. 8, 2006, pp. 923-933.

[14] Farhad, A., John, M.H., Martin, B., A modular and high-precision motion control system with an integrated motor, IEEE/ASME Transactions on Mechatronics, Vol.12, No. 3, 2007, pp. 317-329.

[15] Begovich, O., Sánchez, E.N., Maldonado, M., TakagiSugeno fuzzy scheme for real-time trajectory tracking of an underactuated robot, IEEE Transactions on Control Systems T., Vol. 10, No. 1, 2002, pp. 14-20.

[16] Benitez, V.H., Sánchez, E.N., Loukianov, A.G., Neural identification and control for linear induction motors, 


\section{Intelligent Positioning Fuzzy Servomechanism Under PWM Nonlinear Loads, D.Rangel et al., 87-100}

Journal of Intelligent Fuzzy Systems, Vol. 16, No. 1, 2005, pp. 33-55.

[17] Zadeh, L.A., Fuzzy sets, Information and Control, Vol. 8, 1965, pp. 338-353.

[18] Chen, Y., Wong, C., Implementation of TakagiSugeno model-based fuzzy control using an adaptive gain controller, IEE Proc.-Control Theory Appl., Vol. 147, No. 5, September, 2000, pp. 509-514.

[19] Papoulis, A., Probability, random variables and stochastic processes, McGraw-Hill, New York (1965).

\section{Acknowledgments}

The authors would like to thank Carlos R. Luna, Elohym G. Gayosso and Raul R. Hernández for their technical assistance. They also want to acknowledge Silvia C. Stroet from the Engineering Faculty at Universidad Autónoma de Querétaro for helping with the English proofreading of this document. 


\section{Authors' Biography}

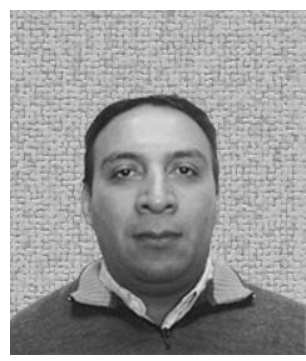

\section{Domingo RANGEL-MIRANDA}

He earned both his B.S. degree in electromechanical engineering and his M.Sc. degree in electronics from the Universidad Nacional Autónoma de Mexico (UNAM) in Mexico City. He belongs to the academic group of the Centro de Física Aplicada y Tecnología Avanzada, Universidad Nacional Autónoma de México (UNAM), Querétaro City, Mexico. He has taught in the undergraduate program (Automation Engineering) at the Universidad Autónoma de Querétaro, Universidad Tecnológica de Querétaro (Electronics and Automation) and UNAM (Advanced Technology). His main interest is in embedded electronics and intelligent mechatronic systems.

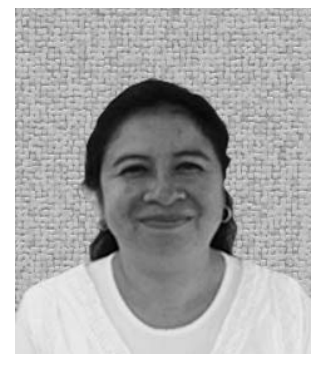

\section{Ana Leonor RIVERA}

Her area of research is mathematical analysis of signals in particular physical systems. Under this subject, she has more than 20 published papers and one book in press. She belongs to the National System of Researchers of CONACyT Mexico, level I. She earned her PhD degree in sciences (physics) from Universidad Nacional Autónoma de México, in Mexico City. Currently, she is a researcher at the Centro de Física Aplicada y Tecnología Avanzada (UNAM), Querétaro City, Mexico, and teaches in the undergraduate Technology major at UNAM. She is member of Sociedad Mexicana de Física and the International Centre for Theoretical Physics in Trieste, Italy.

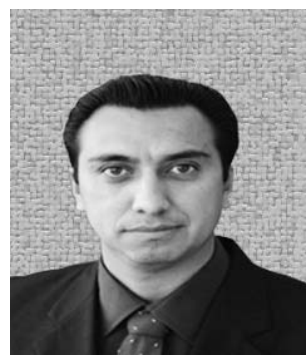

\section{Pedro Daniel ALANÍZ-LUMBRERAS}

He is a professor in the Faculty of Engineering of Universidad Autónoma de Querétaro, where he is the head of the Design and Technology Innovation Center. He has been coordinator of several regional projects. His main research areas of interest are mechatronic systems analysis, bio-mechatronic systems and digital signal processing. 


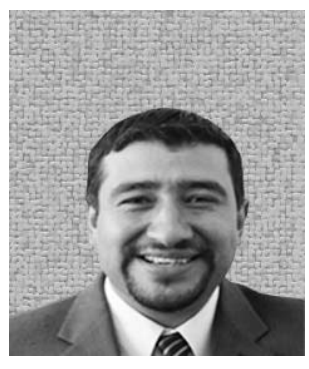

\section{Rodrigo CASTAÑEDA-MIRANDA}

He earned his PhD degree in engineering from Universidad Autónoma de Querétaro. He belongs to the National System of Researchers of CONACyT Mexico, level I. He was advisor for the creation of six technological enterprises. Currently, he is the president of UPSZ. He was awarded the National Prize ADIAT for technological innovation in 2004 and the European Society of Agricultural Engineers-Eurageng outstanding paper award in 2008. His area of research is electronic systems in automation.

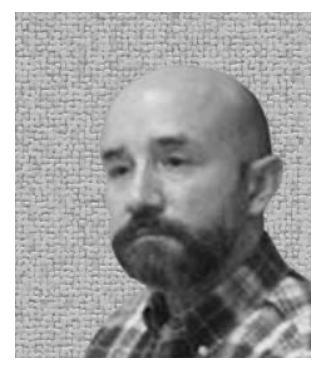

\section{Víctor Manuel CASTAÑO-MENESES}

He received the M.Sc and Ph.D. degrees from the Universidad Nacional Autónoma de México (UNAM) and spent 2 years as a postdoctoral fellow at IBM's Thomas J. Watson Research Center (New York). He has authored and co-authored over 500 peer-review papers, is member of the editorial board of over 20 international journals and has received various awards in Mexico, the US and Europe. His interests are in the area of materials science, particularly in developing nano-sized materials for a number of uses, as well as in nonlinear intelligent systems for industrial manufacturing. The re-use of waste materials is also one of his areas of research. He is full-professor and director of the Centro de Física Aplicada y Tecnología Avanzada (CFATA) of the UNAM. 